\author{
Professor Gheorghe HURDUZEU, PhD \\ E-mail: gheorghe.hurduzeu@ rei.ase.ro \\ The Bucharest University of Economic Studies \\ Professor Radu LUPU, PhD \\ E-mail: radu.lupu@ rei.ase.ro \\ The Bucharest University of Economic Studies \\ Senior researcher Iulia LUPU, PhD \\ E-mail: iulia_lupu@icfm.ro \\ Center for Financial and Monetary Research "Victor Slăvescu" \\ Associate Professor Radu Ion FILIP, PhD \\ E-mail: radu.filip@ rei.ase.ro \\ The Bucharest University of Economic Studies
}

\title{
TRANSMISSION OF EXTERNAL SHOCKS ON THE ROMANIAN CAPITAL MARKET
}

\begin{abstract}
The study of the contagion phenomenon allows an understanding of how the shocks transmitted from the global economy can affect the dynamics of financial markets in a certain country. This paper employs the Diebold-Yilmaz methodology to analyse how the Romanian capital market reacts to shocks transmitted from foreign capital markets on several channels: the direct one of returns, the one of volatilities and that of liquidity. We estimated the indicator for a group of 26 countries, from 2008 to 2019 based on daily frequency data obtained from the Bloomberg platform. In general, it can be stated that Romania receives more spillover than it transmits, on each of the three channels. The most important impact comes from developed countries in the region, namely Austria, Germany, the Netherlands and to a lesser extent from the USA. As for the links with the smaller capital markets in the region, Romania has the tendency to receive spillover from the Czech Republic and Poland and to bi-directionally exchange shocks with Bulgaria and Hungary.

Keywords: spillover, volatility, shock transmission, stock exchange.

JEL Classification: G15, G11, C58

1. Introduction

In the last decades, the intensification of global financial integration has led to increased capital mobility, but also to the spread of volatilities. In the economic literature, the phenomenon of contagion is described as a statistical property of the returns of financial assets to show high levels of correlations when
\end{abstract}

DOI: 10.24818/18423264/55.1.21.03 
they have negative values and low levels of correlations when the returns are positive. As mentioned in Lupu (2012), the contagion issue had gain attention mainly due to its negative connotation, being consociated with financial crises. Going more deeply, there are studies (Niţoi and Pochea, 2020) that confirm the presence of contagion during tumultuousness periods, especially between other markets.

Closely related to the concept of contagion, the spillover phenomenon refers to the transmission of shocks from one financial market to another. In the literature, this phenomenon is mainly the volatility's prerogative (which denotes the risk and uncertainty of financial assets), respectively a description of how the magnitude of the returns is transmitted from one market to another, or from one asset to another. The spillover phenomenon aims to quantify the extent to which financial markets or financial assets tend to transmit shocks, knowledge of which is important for risk management, investment and diversification strategies, surveillance, early warning systems or crisis management. The transmission of volatility on financial markets is also analysed in conjunction with the synchronization of business cycles or economic growth.

An early validation of the spread of volatility between developed markets was first performed by Eun and Shim (1989) using the VAR (vector autoregressive) methodology. This analysis presented a way to quantify the phenomenon of transmission of volatility between markets and showed that the US financial market has the highest impact on the other developed markets.

In fact, most studies that investigated the link between yields and volatilities of financial assets are oriented towards countries with advanced economies, where financial markets are better developed.

\section{Literature Review}

Engle, Ito, and Lin (1990) use an univariate GARCH model for calculating financial asset volatilities and the VAR framework to estimate the impulseresponse functions of the impact of a shock localized in one country at one point in time on the volatility from other country, in one day in the future. The results showed the manifestation of the spillover phenomenon for the USD/JPY exchange rate.

The BEKK model (after the name of the authors Baba, Engle, Kraft, and Kroner) developed in 1990, which is based on the GARCH model, was used in the analysis for its advantages, but also because the results that support the idea that negative profitability affects volatility to a greater extent than positive shocks (Black, 1976; Christie, 1982) are considered.

Subsequently, other studies were conducted in the same field by Leachman and Frances (1996), Bekaert and Harvey (1997) and Ng (2000), who also used the GARCH methodology for estimating volatility and various means of measuring the spillover phenomenon. The importance of the GARCH model in identifying the type of correlations in European capital markets is underlined in Lupu (2015).

Using a DCC-MIDAS model, Moagăr-Poladian et al. (2019) introspect the 
comovement phenomenon for the Czech Republic, Hungary, Poland and Romania and found that the correlation was stronger after 2004, and more powerful during the European sovereign debt crisis compared to the global financial crisis. The link of the Romanian market with the other countries in the region was more noticeable in the post-crisis period.

The limitations of the asymmetric BEKK model (the use of a large number of parameters and the difficulties in interpreting them) favoured the development of alternative methods, such as Engle's (2002) dynamic conditional correlation model. Versions of this model were extended by Cappiello et al. (2006). Previously, in order to diminish the complexity of multivariate models, Bollerslev (1990) proposed the use of a constant correlation hypothesis.

Barndorff-Nielsen and Shephard (2002) and Barndorff-Nielsen et al. (2008) break down the volatility achieved in semi-dispersion at the bottom and semi-dispersion at the top. Baruník et al. (2016) improve the propagation model by incorporating the concept of good volatility and bad volatility to capture the asymmetric effect.

Understanding how volatility is transmitted from developed to emerging countries has been approached in the literature by using different methods and periods, the obtained results being mixed. For example, for the Asian area, older studies argue that the US stock market has a greater influence on local markets compared to the influence of regional markets (John Wei et al., 1995), while Miyakoshi (2003) argues in favour of greater influences from the Japanese stock market compared to the US, in terms of volatility.

The contagion phenomenon appears extensively debated in the literature following the Asian crisis of 1997 and the Russian crisis of 1998. The main works dealing with this phenomenon are Claessens and Forbes (2001), Forbes and Rigobon (2002), which aim to quantify the properties of financial returns before and after the events that triggered the crisis.

A large group of works in the field of contagion have analysed mainly the causes underlying the manifestation of this phenomenon. Some of these are considered to be fundamental in nature, as opposed to indirect ones.

The spillover effect is considered to be one of the fundamental phenomena that underlie the manifestation of contagion, by the fact that it refers to the analysis of shocks, respectively of events that affect the evolution of economic variables. These shocks can be represented by the commercial relations, the manifestations of the competitive depreciation, the financial relations or may be determined by the behaviour of the investors, respectively, the phenomenon of transmission of the liquidity shocks or the manifestation of events of the informational asymmetry.

\section{Data and methodology}

Our analysis uses the methodological framework developed by Diebold and Yilmaz $(2009,2012)$. These papers analyse the propagation of volatility of yields using stock indices from developed and emerging countries.

DOI: $10.24818 / 18423264 / 55.1 .21 .03$ 
Diebold and Yilmaz (2009) introduce new methods of measuring the spillover effect for yields and volatilities, in addition to the widely used multivariate GARCH models. The authors analyse the effect of total spillover (from one market to all analysed markets / from all markets to a certain market) and argue the existence of different dynamics for their propagation: in the case of stock returns, there is a slight growth trend (associated with the increase of the degree of integration of financial markets), without sudden movements, while in the case of volatilities, the situation is the reverse - there are no trends, but sudden changes (associated with events related to crises).

Diebold and Yilmaz (2012) use dispersion decomposition of forecast errors to determine the importance of an asset market given its ability to predict the price of a related asset in a robust manner. The new methodology measures the directional spillover effect, eliminating the eventual dependence of the results on the data ordering.

For the analysis of the external spillover effects on the Romanian capital market, several series of daily stock index prices for European countries were obtained from the Bloomberg platform, to which we added the USA.

The set includes both developed and emerging and frontier European markets, from January 2007 to November 2019.

Diebold and Yilmaz (2009) methodology involves measuring the propagation of volatility (in times of crisis, but also outside them) based on the decomposition of dispersion of forecast errors from a VAR (autoregressive vector) model. These errors are divided into parts that can be attributed to the various shocks applied to the system. We can thus obtain information about which is the portion of the variance error for a period prediction for variable $\mathrm{x}_{1}$ as a result of shocks applied to $\mathrm{x} 1$ or the portion of the variance error for a period prediction for the same variable as a result of shocks applied to the variable $\mathrm{x}_{2}$.

The volatility spillover index derives from the VAR(p) model with $\mathrm{N}$ variable, with the form:

$$
x_{t}=\sum_{i=1}^{p} \Phi_{i} x_{t-i}+\epsilon_{t}
$$

where $x_{t}=\left(x_{1, t}, \ldots, x_{N, t}\right)^{\prime}$ is the vector of logarithmic returns from time $t$ for all stock indexes analysed, $\phi$ is the matrix of parameters of the VAR model, and $\varepsilon$ is the vector of errors with zero mean and constant covariance.

From this model, we decompose the variance and obtain the Spillover Index, calculated as follows:

$$
S(H)=\frac{\sum_{i, j=1, i \neq j}^{N} \theta_{\mathrm{ij}}(H)}{\sum_{i, j=1}^{N} \theta_{\mathrm{ij}}(H)}
$$

where the numerator is the sum of the volatility contributions "from others", and the denominator represents the sum of the contributions "to others including one's own contribution".

DOI: $10.24818 / 18423264 / 55.1 .21 .03$ 
Given that in decomposing the variance based on the Cholesky method, the order in which the variables are arranged is important. For our analysis we will use the method developed by Pesaran and Shin (1998), which eliminates this problem.

\section{Results and discussion}

The calculation of the spillover index for the entire period that was analysed and for the indexes for 29 countries was calculated repeatedly for a 100 day mobile window.

Analysis corresponds to the application of the Diebold-Yilmaz methodology on the stock index returns, with daily frequency. A VAR with 2 lags was used, and the forecast was realized for a period of 4 days. The Figure 1 below shows this dynamic.

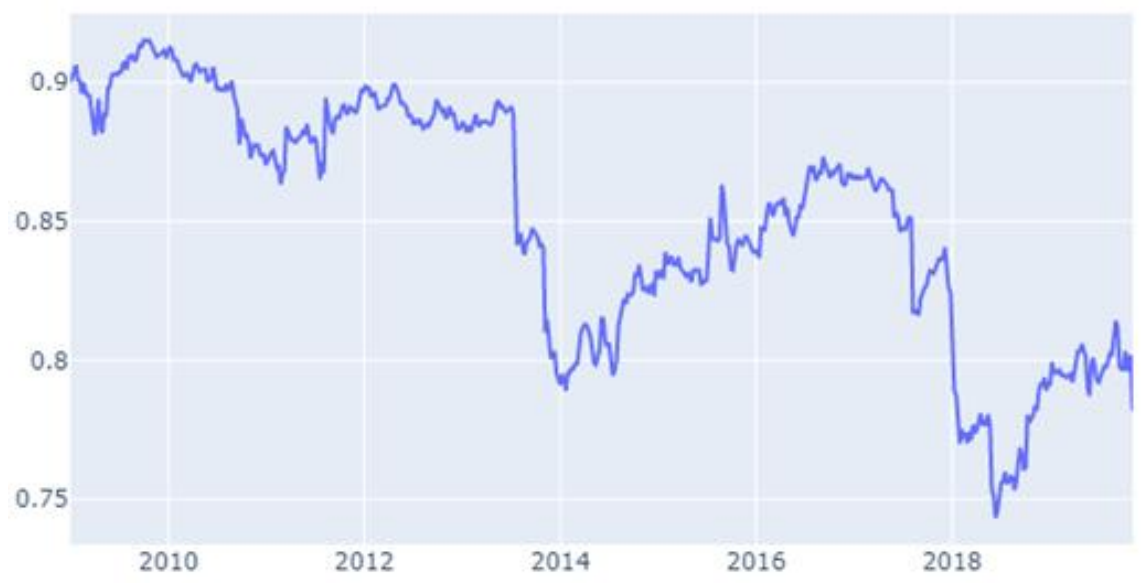

Figure 1. Dynamics of the spillover index for stock index returns based on a 100-day moving window

During this period, one can observe a tendency to reduce the proportions of forecast errors corresponding to the shocks applied to the stock indices without the contribution of their own shocks, as a weight in the total amount of error of the variances.

The table below (Table 1) shows the breakdown of the forecast error dispersion for 4 days before, following Cholesky's factorization method, within a VAR(2) model.

Table 1. The matrix of spillover values for all the countries analysed and for the whole period for yields (prediction for 4 periods and VAR with 2 lags)

\begin{tabular}{|l|r|r|r|r|r|r|r|r|r|r|r|r|r|r|}
\hline & S\&P500 & Germany & France & UK & Austria & Belgium & Bulgaria & Croatia & Cyprus & Czech R. & Denmark & Estonia & Finland & Greece \\
\hline S\&P500 & 0.151 & 0.066 & 0.066 & 0.063 & 0.048 & 0.059 & 0.001 & 0.019 & 0.007 & 0.028 & 0.040 & 0.006 & 0.050 & 0.013 \\
\hline Germany & 0.044 & 0.092 & 0.078 & 0.064 & 0.052 & 0.065 & 0.002 & 0.014 & 0.007 & 0.029 & 0.046 & 0.006 & 0.058 & 0.016 \\
\hline France & 0.042 & 0.072 & 0.085 & 0.066 & 0.052 & 0.068 & 0.002 & 0.012 & 0.008 & 0.030 & 0.045 & 0.006 & 0.058 & 0.017 \\
\hline UK & 0.047 & 0.067 & 0.074 & 0.095 & 0.051 & 0.065 & 0.002 & 0.014 & 0.007 & 0.031 & 0.047 & 0.005 & 0.057 & 0.014 \\
\hline
\end{tabular}


Gheorghe Hurduzeu, Radu Lupu, Iulia Lupu, Radu Ion Filip

\begin{tabular}{|c|c|c|c|c|c|c|c|c|c|c|c|c|c|c|}
\hline Austria & 0.040 & 0.058 & 0.062 & 0.054 & 0.099 & 0.060 & 0.003 & 0.017 & 0.011 & 0.047 & 0.044 & 0.008 & 0.054 & 0.020 \\
\hline Belg & 041 & 0.065 & 0.073 & 0.062 & 05 & 0.092 & 0.002 & 0.0 & 0.009 & 0.032 & 0.046 & 0.007 & .057 & .0 \\
\hline Bulgaria & 0.046 & 0.025 & 0.023 & 0.024 & 0.025 & 0.023 & 0.410 & 0.039 & 0.016 & 0.030 & 0.023 & 0.023 & 0.026 & .011 \\
\hline Croatia & 0.044 & 0.039 & 0.036 & 0.038 & 0.044 & 0.037 & 0.015 & 0.252 & 0.019 & 0.046 & 0.033 & 0.017 & 0.033 & 0.017 \\
\hline Cyprus & 0.021 & 0.027 & 0.031 & 0.025 & 0.035 & 0.033 & 0.007 & 0.025 & 0.339 & 0.037 & 0.027 & 0.008 & 0.028 & 0.092 \\
\hline Czech R. & 0.039 & 0.045 & 0.049 & 0.045 & 0.064 & 0.049 & 0.007 & 0.025 & 0.015 & 0.129 & 0.043 & 0.013 & 0.042 & 0.025 \\
\hline Den & 0.041 & 0.058 & 0.061 & 0.057 & 0.050 & 0.059 & 0.005 & 0.014 & 0.009 & 0.037 & 0.114 & 0.011 & .058 & 0.019 \\
\hline Estonia & 0.043 & 0.030 & 0.029 & 0.028 & 0.033 & 0.034 & 0.016 & 0.026 & 0.010 & 0.034 & 0.039 & 0.286 & 0.032 & 0.011 \\
\hline Finlar & 0.040 & 0.064 & 0.069 & 0.060 & 0.054 & 0.063 & 0.002 & 0.013 & 0.008 & 0.032 & .050 & 0.007 & 0.100 & 0.016 \\
\hline Greece & 0.028 & 0.042 & 0.045 & 0.035 & 0.043 & 0.045 & 0.003 & 0.014 & 0.060 & 0.040 & 0.036 & 0.007 & 0.036 & 0.219 \\
\hline Hungary & 0.037 & 0.049 & 0.052 & 0.046 & 0.051 & 0.048 & 0.003 & 0.018 & 0.011 & 0.051 & 0.039 & 0.009 & 0.042 & 0.019 \\
\hline Irland & 0.041 & 0.056 & 0.064 & 0.058 & 0.053 & 0.065 & 0.002 & 0.012 & 0.009 & 0.032 & 0.050 & 0.007 & 0.054 & 0.019 \\
\hline Italy & 0.036 & 0.067 & 0.076 & 0.058 & 0.054 & 0.065 & 0.002 & 0.011 & 0.008 & 0.033 & 0.041 & 0.006 & 0.055 & 0.020 \\
\hline Latvia & 0.026 & 0.016 & 0.018 & 0.019 & 0.021 & 0.020 & 0.015 & 0.0 & 0.008 & 0.020 & 0.023 & 0.03 & 0.022 & 0.008 \\
\hline Lithuania & 0.042 & 0.027 & 0.026 & 0.025 & 0.035 & 0.031 & 0.025 & 0.027 & 0.011 & 0.038 & 0.032 & 0.078 & 0.029 & 0.012 \\
\hline Malta & 0.005 & 0.004 & 0.003 & 0.004 & 0.006 & 0.005 & 0.009 & 0.008 & 0.005 & 0.003 & 0.007 & 0.005 & 0.002 & 0.004 \\
\hline $\mathrm{Ne}$ & 0.044 & 0.068 & 0.076 & 0.069 & 0. & 0.068 & 0.002 & 0. & 8 & 0.032 & 0. & 0.0 & .057 & .0 \\
\hline Polond & 0.039 & 0.053 & 0.052 & 0.049 & 0.052 & 0.048 & 0.004 & 0.019 & 0.013 & 0.053 & 0.041 & 0.009 & 0.047 & 0.023 \\
\hline Portugal & 0.035 & 0.057 & 0.065 & 0.056 & 0.054 & 0.062 & 0.003 & 0.011 & 0.011 & 0.035 & 0.046 & 0.008 & 0.053 & 0.024 \\
\hline Slovenia & 0.054 & 0.030 & 0.030 & 0.031 & 0.034 & 0.031 & 0.015 & 0.043 & 0.011 & 0.029 & 0.033 & 0.015 & 0.023 & 0.014 \\
\hline Spain & 0.038 & 0.064 & 0.075 & 0.058 & 0.054 & 0.065 & 0.002 & 0.012 & 0.009 & 0.033 & 0.040 & 0.005 & 0.053 & 0.020 \\
\hline Sweden & 0.041 & 0.068 & 0.070 & 0.064 & 0.054 & 0.062 & 0.002 & 0.013 & 0.007 & 0.032 & 0.051 & 0.006 & 0.068 & 0.015 \\
\hline Romania & 0.038 & 0.038 & 0.038 & 0.038 & 0.048 & 0.042 & 0.011 & 0.038 & 0.019 & 0.055 & 0.038 & 0.021 & 0.034 & 0.023 \\
\hline
\end{tabular}

\begin{tabular}{|c|c|c|c|c|c|c|c|c|c|c|c|c|c|}
\hline & Hungary & Irland & Italy & Latvia & Lithuania & Malta & Netherlands & Polond & Portugal & Slovenia. & Spain & Sweden & Romania \\
\hline S\&P500 & 0.027 & 0.040 & 0.051 & 0.001 & 0.005 & 0.000 & 0.067 & 0.032 & 0.038 & 0.003 & 0.051 & 0.056 & 0.014 \\
\hline Germany & 0.026 & 0.042 & 0.063 & 0.001 & 0.004 & 0.000 & 0.072 & 0.033 & 0.046 & 0.002 & 0.060 & 0.063 & 0.015 \\
\hline France & 0.026 & 0.044 & 0.066 & 0.001 & 0.004 & 0.000 & 0.074 & 0.031 & 0.049 & 0.002 & 0.065 & 0.061 & 0.014 \\
\hline UK & 0.026 & 0.045 & 0.056 & 0.001 & 0.005 & 0.000 & 0.075 & 0.032 & 0.047 & 0.002 & 0.056 & 0.062 & 0.016 \\
\hline Austria & 0.031 & 0.044 & 0.056 & 0.002 & 0.008 & 0.000 & 0.061 & 0.037 & 0.048 & 0.004 & 0.056 & 0.055 & 0.022 \\
\hline Belgium & 0.026 & 0.048 & 0.062 & 0.001 & 0.006 & 0.000 & 0.071 & 0.030 & 0.050 & 0.003 & 0.061 & 0.058 & 0.016 \\
\hline Bulgaria & 0.014 & 0.017 & 0.020 & 0.009 & 0.033 & 0.002 & 0.026 & 0.022 & 0.021 & 0.015 & 0.021 & 0.024 & 0.033 \\
\hline Croatia & 0.025 & 0.025 & 0.031 & 0.002 & 0.017 & 0.001 & 0.043 & 0.034 & 0.026 & 0.014 & 0.032 & 0.035 & 0.045 \\
\hline Cyprus & 0.024 & 0.025 & 0.029 & 0.002 & 0.007 & 0.000 & 0.030 & 0.030 & 0.031 & 0.004 & 0.031 & 0.025 & 0.028 \\
\hline Czech R. & 0.040 & 0.035 & 0.046 & 0.003 & 0.013 & 0.000 & 0.051 & 0.049 & 0.041 & 0.006 & 0.046 & 0.043 & 0.035 \\
\hline Denmark & 0.027 & 0.047 & 0.049 & 0.003 & 0.009 & 0.000 & 0.062 & 0.033 & 0.047 & 0.004 & 0.048 & 0.060 & 0.021 \\
\hline Estonia & 0.021 & 0.026 & 0.027 & 0.013 & 0.073 & 0.000 & 0.033 & 0.029 & 0.030 & 0.012 & 0.024 & 0.028 & 0.034 \\
\hline Finland & 0.025 & 0.044 & 0.057 & 0.001 & 0.006 & 0.000 & 0.066 & 0.033 & 0.047 & 0.002 & 0.054 & 0.069 & 0.015 \\
\hline Greece & 0.026 & 0.035 & 0.047 & 0.002 & 0.006 & 0.000 & 0.043 & 0.036 & 0.045 & 0.003 & 0.047 & 0.034 & 0.023 \\
\hline Hungary & 0.168 & 0.035 & 0.046 & 0.002 & 0.009 & 0.000 & 0.051 & 0.052 & 0.041 & 0.005 & 0.047 & 0.042 & 0.028 \\
\hline Irland & 0.025 & 0.122 & 0.052 & 0.001 & 0.006 & 0.000 & 0.065 & 0.032 & 0.044 & 0.003 & 0.053 & 0.056 & 0.017 \\
\hline Italy & 0.026 & 0.041 & 0.097 & 0.001 & 0.004 & 0.000 & 0.067 & 0.030 & 0.054 & 0.002 & 0.075 & 0.055 & 0.014 \\
\hline Latvia & 0.007 & 0.017 & 0.014 & 0.546 & 0.045 & 0.001 & 0.019 & 0.014 & 0.017 & 0.012 & 0.011 & 0.016 & 0.017 \\
\hline Lithuania & 0.021 & 0.023 & 0.022 & 0.021 & 0.292 & 0.001 & 0.029 & 0.029 & 0.029 & 0.015 & 0.020 & 0.022 & 0.037 \\
\hline Malta & 0.004 & 0.005 & 0.004 & 0.001 & 0.006 & 0.879 & 0.004 & 0.002 & 0.004 & 0.007 & 0.004 & 0.003 & 0.008 \\
\hline Netherlands & 0.026 & 0.046 & 0.060 & 0.001 & 0.005 & 0.000 & 0.087 & 0.032 & 0.047 & 0.002 & 0.058 & 0.060 & 0.016 \\
\hline
\end{tabular}


Transmission of External Shocks on the Romanian Capital Market

\begin{tabular}{|l|l|l|l|l|l|l|l|l|l|l|l|l|l|}
\hline Polond & 0.044 & 0.037 & 0.044 & 0.002 & 0.010 & 0.000 & 0.054 & 0.143 & 0.040 & 0.004 & 0.045 & 0.049 & 0.026 \\
\hline Portugal & 0.027 & 0.041 & 0.063 & 0.002 & 0.008 & 0.000 & 0.060 & 0.031 & 0.113 & 0.003 & 0.066 & 0.050 & 0.018 \\
\hline Slovenia & 0.019 & 0.026 & 0.025 & 0.007 & 0.019 & 0.001 & 0.035 & 0.023 & 0.025 & 0.343 & 0.025 & 0.027 & 0.033 \\
\hline Spain & 0.027 & 0.042 & 0.076 & 0.001 & 0.004 & 0.000 & 0.066 & 0.030 & 0.057 & 0.002 & 0.098 & 0.054 & 0.015 \\
\hline Sweden & 0.024 & 0.045 & 0.056 & 0.001 & 0.004 & 0.000 & 0.068 & 0.033 & 0.044 & 0.002 & 0.055 & 0.099 & 0.015 \\
\hline Romania & 0.034 & 0.032 & 0.033 & 0.005 & 0.022 & 0.001 & 0.041 & 0.040 & 0.034 & 0.013 & 0.034 & 0.034 & 0.195 \\
\hline
\end{tabular}

Each ij in the table is an estimate of the contribution to the dispersion of the forecast errors of variable $i$, which come from the innovations (shocks) applied to variable j. Also, the sum of the rows and columns without a diagonal shows the directional propagation of volatility, noted with "contribution from others" and "contribution to others" respectively.

In order to have a clearer picture of how the spillover effect has manifested for the entire period under discussion, we can observe in the Figure 2 the values for portions of shocks transmitted to others and those received from others for all stock indexes.

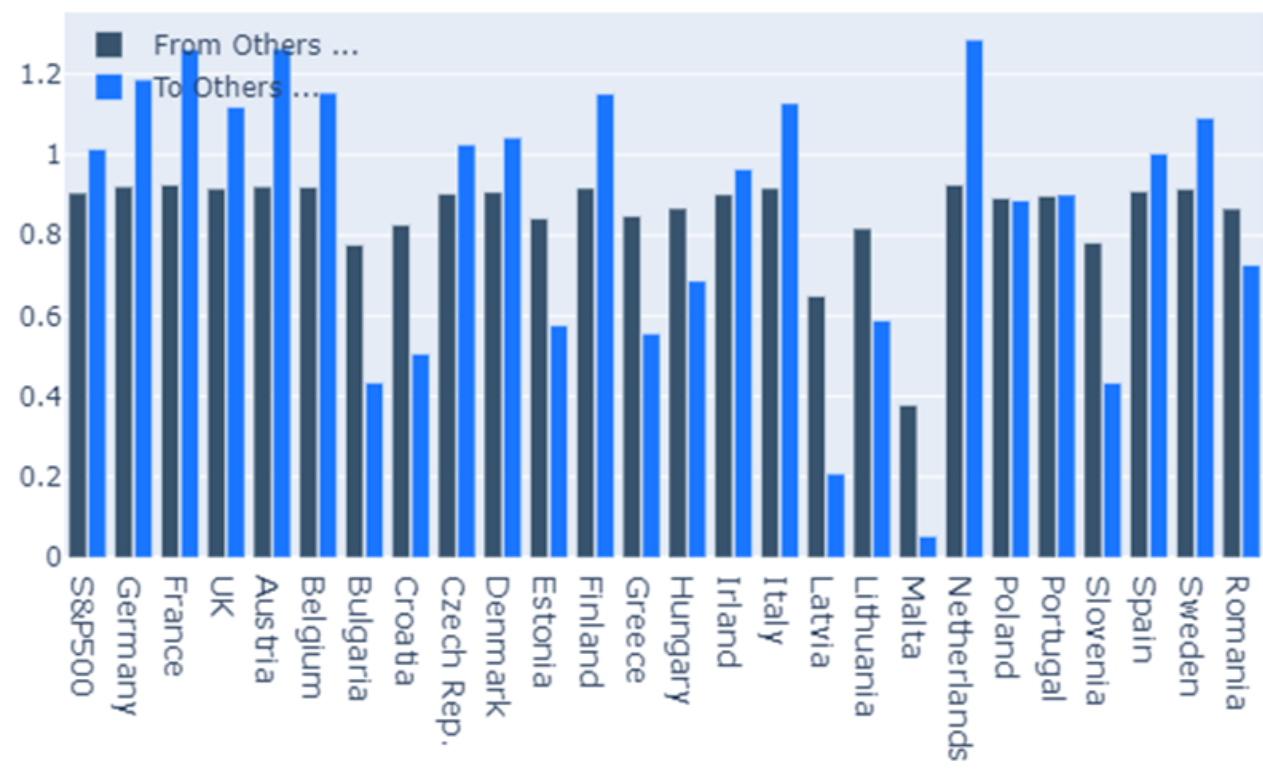

Figure 2. The spillover effect received and transmitted within the group of analysed stock indexes, for the whole period, for the set of logarithmic returns

We note that for the stock exchange indices of developed countries we have high values in terms of the pressure transmitted to others, while for the other countries, the values are higher for the received spillover, including the case of Romania.

The spillover effect regarding the transmission of shocks related with

\section{DOI: 10.24818/18423264/55.1.21.03}


Gheorghe Hurduzeu, Radu Lupu, Iulia Lupu, Radu Ion Filip

volatilities was achieved for the volatilities obtained by estimating the GARCH model $(1,1)$ for the daily returns of all stock indices over the analysed period. Applying the Diebold-Yilmaz methodology with the Pesaran-Shin algorithm allowed us to obtain the results presented in Table 2 .

Table 2. The matrix of spillover values for all the countries analysed and for the whole period for volatilities

(prediction for 4 periods and VAR with 2 lags)

\begin{tabular}{|c|c|c|c|c|c|c|c|c|c|c|c|c|c|c|}
\hline & 500 & any & nce & K & stria & gium & Bulgaria & Croatia & Cyprus & ech R. & Denmark & Estonia & nland & Gree \\
\hline 55 & & 54 & & 153 & & & & & & & & & & \\
\hline & & & & 6 & & & & & & & & & & \\
\hline ance & & & & & & & & & & & & & & \\
\hline JK & 26 & 071 & & 24 & $0<$ & 0 & & & & & & & & .0 \\
\hline str & & 58 & & 4 & 0.132 & 5 & 34 & & .005 & $.04 \varepsilon$ & 03 & 0 & ( & 0 \\
\hline & 227] & 067 & & 063 & 0.056 & & & & & 029 & & 00 & & .0 \\
\hline Iga & 09 & 11 & 0.009 & 015 & 1 & 12 & 579 & 22 & 004 & 01 & 02 & 01 & 013 & .00 \\
\hline ia & 1 & 034 & 4 & 045 & & 0.0 & 0.014 & & 0.007 & .06 & 03 & J1 & & .0 \\
\hline yprus & 05 & 016 & 19 & 016 & 017 & 0.018 & 0.001 & 011 & 612 & $.03 c$ & 01 & 00 & 02 & 0.085 \\
\hline & & & & 34 & & & & & & & & & & \\
\hline $\mathrm{nma}$ & 16 & 56 & 63 & 061 & 049 & 060 & .004 & 013 & .003 & .035 & 174 & 01 & .055 & 0.014 \\
\hline tonia & & & & & & & & & & & & & & \\
\hline nland & 3 & 66 & 75 & 060 & 2 & 9 & 22 & 1 & .004 & 029 & 04 & $0 c_{-}$ & 1 & \\
\hline & & & & & & & & & & & & & & \\
\hline lunga & 24 & 44 & 45 & 034 & 77 & 16 & 02 & 12 & 04 & 045 & 034 & 021 & 3 & \\
\hline 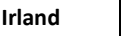 & & & & & & & & & & & & & & \\
\hline taly & 23 & 74 & 37 & 054 & 3 & 1 & 1 & 11 & 0.005 & 0.030 & 03 & 00 & 40 & \\
\hline$\cdots$ & & & & & & & & & & & & & & \\
\hline ithua & 2 & 1 & 0.022 & 8 & 0 & 2 & 6 & 7 & 35 & 0.020 & & & & \\
\hline nalta & & 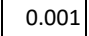 & 0.001 & 0.000 & 0.000 & 0.003 & & 0.002 & 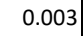 & . & & & 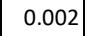 & . \\
\hline Nethe & 8 & 0.077 & 088 & 077 & 0.052 & 0.078 & 0.002 & & & 0.029 & & & & \\
\hline olond & 0.020 & 0.050 & 0.050 & 0.050 & 0.055 & 0.047 & 0.004 & 0.015 & 0.004 & 050 & | & 014 & 041 & 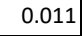 \\
\hline Por & & & & & & & & & & & & & & \\
\hline loven & 0.023 & 0.026 & 0.025 & 0.027 & 0.028 & 0.022 & 0.029 & 0.046 & 0.005 & 028 & $0<4$ & $0<0$ & 019 & 0.00 \\
\hline pait & & & & & & & & & & & & & & \\
\hline wed & 26 & 0.074 & 18 & 0.068 & 0.052 & 0.066 & 0.001 & 10 & & 27 & & 006 & 070 & .001 \\
\hline sine & 013 & $0<5$ & 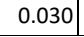 & 0.020 & . & | & 0.011 & .024 & .00 & 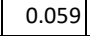 & - & . & 0.02 & 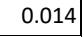 \\
\hline
\end{tabular}

\begin{tabular}{|l|r|r|r|r|r|r|r|r|r|r|r|r|r|}
\hline & Hungary & Irland & Italy & Latvia & Lithuania & Malta & Netherlands & Polond & Portugal & Slovenia. & Spain & Sweden & Romania \\
\hline S\&P500 & 0.012 & 0.039 & 0.045 & 0.002 & 0.006 & 0.000 & 0.073 & 0.027 & 0.032 & 0.005 & 0.039 & 0.048 & 0.014 \\
\hline Germany & 0.016 & 0.030 & 0.068 & 0.002 & 0.004 & 0.000 & 0.085 & 0.032 & 0.045 & 0.005 & 0.064 & 0.061 & 0.010 \\
\hline France & 0.017 & 0.034 & 0.074 & 0.001 & 0.003 & 0.000 & 0.087 & 0.028 & 0.052 & 0.004 & 0.072 & 0.057 & 0.009 \\
\hline UK & 0.016 & 0.035 & 0.053 & 0.001 & 0.004 & 0.000 & 0.090 & 0.034 & 0.048 & 0.004 & 0.053 & 0.064 & 0.010 \\
\hline Austria & 0.023 & 0.040 & 0.059 & 0.001 & 0.006 & 0.001 & 0.069 & 0.040 & 0.052 & 0.004 & 0.057 & 0.051 & 0.020 \\
\hline Belgium & 0.018 & 0.044 & 0.065 & 0.001 & 0.004 & 0.000 & 0.081 & 0.028 & 0.053 & 0.005 & 0.064 & 0.052 & 0.013 \\
\hline Bulgaria & 0.000 & 0.017 & 0.005 & 0.007 & 0.024 & 0.002 & 0.016 & 0.011 & 0.014 & 0.018 & 0.006 & 0.006 & 0.025 \\
\hline
\end{tabular}

DOI: 10.24818/18423264/55.1.21.03 
Transmission of External Shocks on the Romanian Capital Market

\begin{tabular}{|l|l|l|l|l|l|l|l|l|l|l|l|l|l|}
\hline Croatia & 0.006 & 0.010 & 0.025 & 0.003 & 0.018 & 0.000 & 0.042 & 0.033 & 0.037 & 0.017 & 0.029 & 0.024 & 0.024 \\
\hline Cyprus & 0.008 & 0.008 & 0.019 & 0.000 & 0.000 & 0.001 & 0.019 & 0.012 & 0.023 & 0.004 & 0.022 & 0.009 & 0.011 \\
\hline Czech R. & 0.031 & 0.022 & 0.044 & 0.002 & 0.010 & 0.000 & 0.051 & 0.058 & 0.050 & 0.009 & 0.048 & 0.035 & 0.034 \\
\hline Denmark & 0.015 & 0.042 & 0.043 & 0.001 & 0.007 & 0.000 & 0.072 & 0.032 & 0.052 & 0.003 & 0.044 & 0.058 & 0.017 \\
\hline Estonia & 0.020 & 0.016 & 0.012 & 0.014 & 0.084 & 0.003 & 0.022 & 0.028 & 0.023 & 0.007 & 0.014 & 0.020 & 0.026 \\
\hline Finland & 0.019 & 0.042 & 0.056 & 0.001 & 0.004 & 0.000 & 0.071 & 0.033 & 0.048 & 0.006 & 0.054 & 0.074 & 0.012 \\
\hline Greece & 0.014 & 0.030 & 0.045 & 0.000 & 0.002 & 0.000 & 0.038 & 0.026 & 0.042 & 0.005 & 0.050 & 0.018 & 0.015 \\
\hline Hungary & 0.249 & 0.024 & 0.043 & 0.003 & 0.018 & 0.001 & 0.045 & 0.052 & 0.044 & 0.009 & 0.038 & 0.029 & 0.034 \\
\hline Irland & 0.014 & 0.177 & 0.054 & 0.002 & 0.004 & 0.000 & 0.070 & 0.025 & 0.046 & 0.002 & 0.053 & 0.053 & 0.010 \\
\hline Italy & 0.021 & 0.031 & 0.132 & 0.001 & 0.002 & 0.001 & 0.072 & 0.029 & 0.060 & 0.004 & 0.090 & 0.044 & 0.011 \\
\hline Latvia & 0.006 & 0.011 & 0.005 & 0.738 & 0.035 & 0.002 & 0.017 & 0.011 & 0.009 & 0.007 & 0.005 & 0.009 & 0.008 \\
\hline Lithuania & 0.023 & 0.020 & 0.013 & 0.013 & 0.454 & 0.001 & 0.026 & 0.024 & 0.021 & 0.008 & 0.010 & 0.017 & 0.022 \\
\hline Malta & 0.000 & 0.005 & 0.000 & 0.005 & 0.008 & 0.912 & 0.002 & 0.001 & 0.001 & 0.002 & 0.000 & 0.002 & 0.007 \\
\hline Netherlands & 0.016 & 0.038 & 0.060 & 0.002 & 0.004 & 0.000 & 0.112 & 0.031 & 0.047 & 0.004 & 0.058 & 0.060 & 0.010 \\
\hline Polond & 0.036 & 0.028 & 0.038 & 0.003 & 0.009 & 0.000 & 0.056 & 0.208 & 0.048 & 0.004 & 0.044 & 0.044 & 0.022 \\
\hline Portugal & 0.021 & 0.033 & 0.065 & 0.001 & 0.004 & 0.000 & 0.065 & 0.037 & 0.152 & 0.005 & 0.068 & 0.041 & 0.015 \\
\hline Slovenia & 0.005 & 0.015 & 0.016 & 0.008 & 0.018 & 0.001 & 0.033 & 0.019 & 0.027 & 0.454 & 0.019 & 0.020 & 0.034 \\
\hline Spain & 0.021 & 0.033 & 0.094 & 0.001 & 0.002 & 0.001 & 0.070 & 0.029 & 0.062 & 0.005 & 0.132 & 0.041 & 0.012 \\
\hline Sweden & 0.013 & 0.045 & 0.056 & 0.001 & 0.003 & 0.000 & 0.077 & 0.033 & 0.043 & 0.002 & 0.054 & 0.124 & 0.009 \\
\hline Romania & 0.026 & 0.026 & 0.026 & 0.003 & 0.019 & 0.000 & 0.035 & 0.039 & 0.039 & 0.011 & 0.030 & 0.020 & 0.336 \\
\hline
\end{tabular}

The degree of transmission of shocks in terms of volatility, for the entire period is shown in Figure 3.

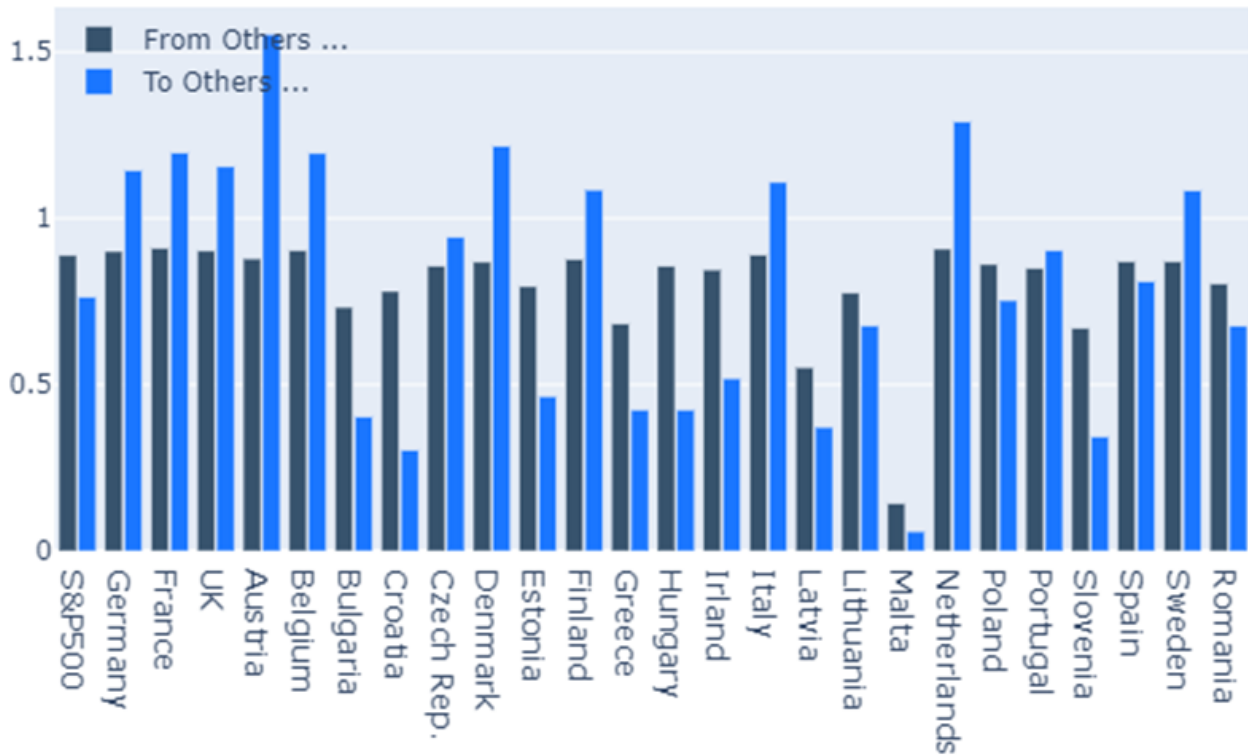

Figure 3. The spillover effect received and transmitted within the group of analysed stock indexes, for the whole period, for the set of volatilities

DOI: 10.24818/18423264/55.1.21.03 
It can also be observed that the transmission of volatility occurs mainly from developed to emerging and frontier countries. As in the case of yields, Romania is more volatile than issuer.

To analyse how Romania participates in this spillover phenomenon, we will analyse this effect only for our country. The results presented in Figure 4 shows us the amount of shocks transmitted at the level of yields in Romania, during the whole analysed period.

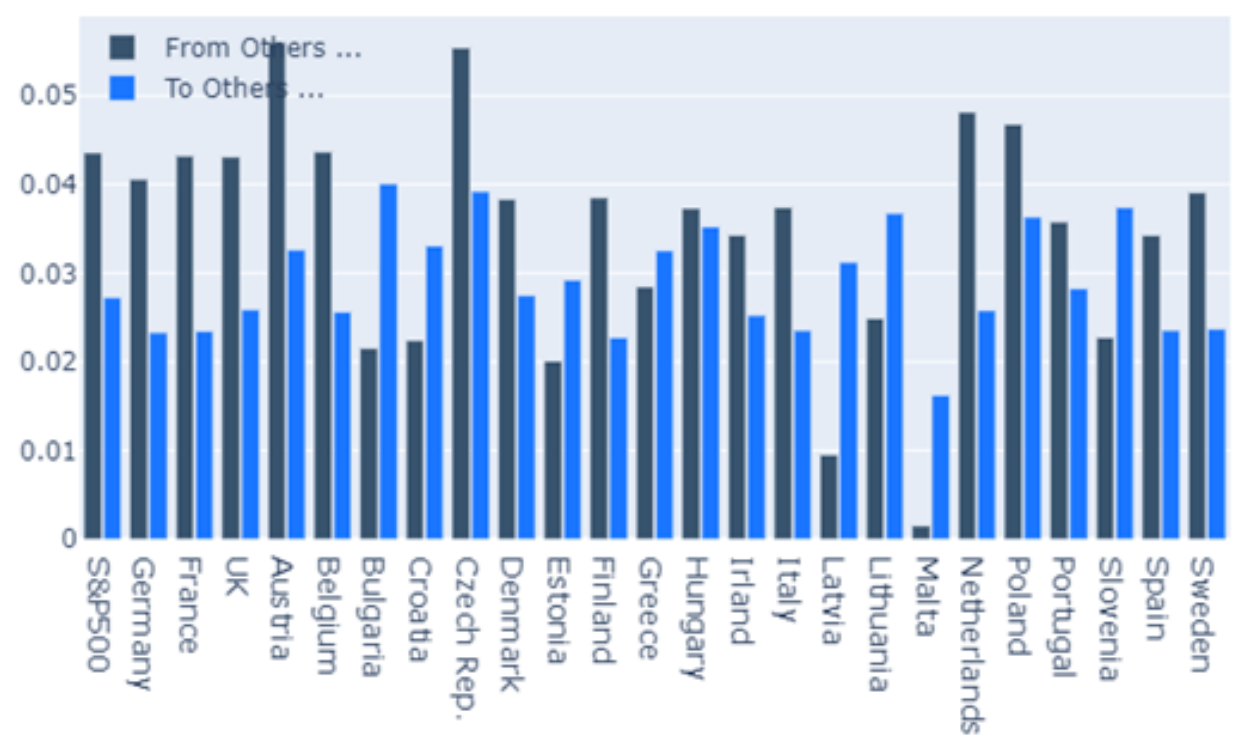

Figure 4. The spillover effect for Romania throughout the analysed period for the transmission of shocks to yields

It is noted that the main channels through which Romania receives shocks in yields are from developed countries, notably Austria, the USA, Germany, France, the UK, but also from countries in the region, such as the Czech Republic, Poland and Hungary.

The same type of analysis was also performed for the dynamics of volatilities. Figure 5 presents the spillover situation for the volatility dynamics for the whole period only for the case of Romania.

We note that, to a large extent, the receipt of volatility shocks is obtained from Austria and the Czech Republic, respectively the developed and emerging countries in the region. Developed countries also have a significant impact, with the S\&P500 and the British capital market making significant contributions. Germany is also at about the same level. 


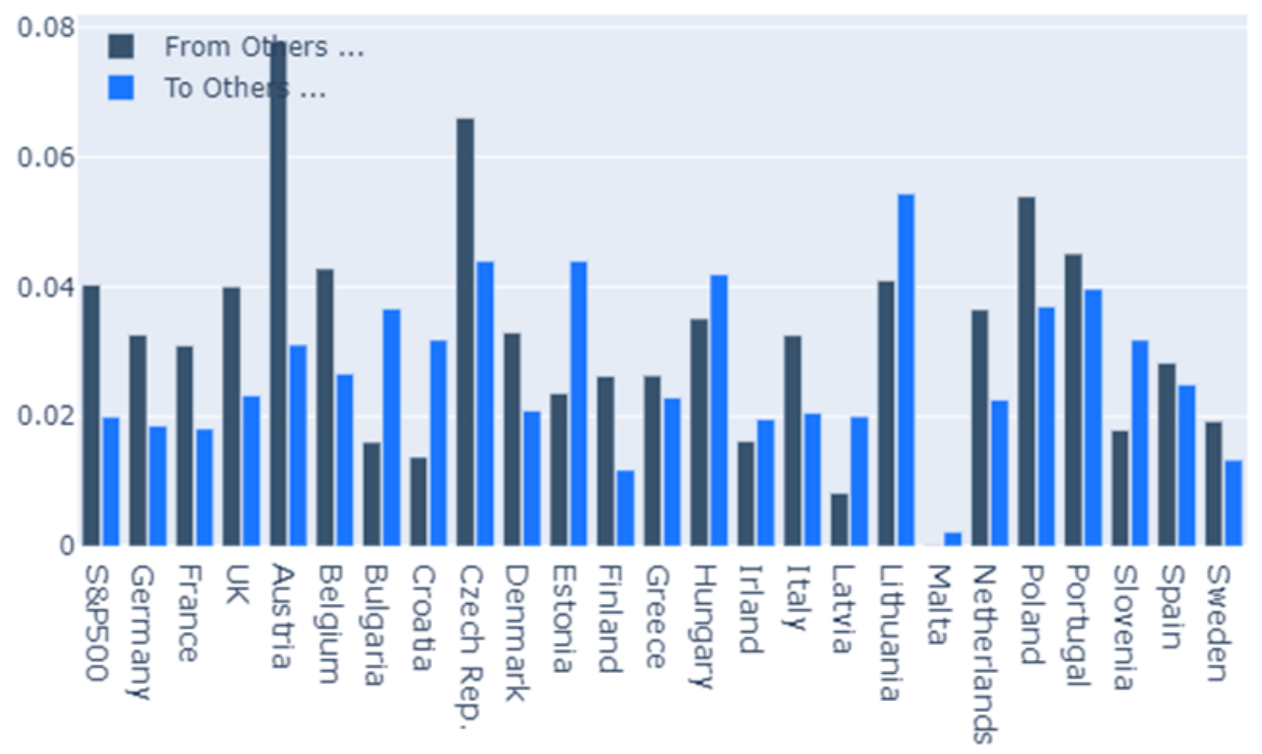

Figure 5. The spillover effect for Romania throughout the analysed period for the transmission of shocks to volatilities

In order to have a more complete view on the dynamics of the shocks that are transmitted to our capital market, a liquidity analysis was conducted in order to understand the extent to which the dynamics of the transactions is determined by the investors' appetite on foreign capital markets.

For the calculation of liquidity, the Amihud indicator (2002) was used, which considers the estimation of an average of the absolute values of logarithmic returns relative to the volume of transactions in each day. The Bloomberg platform allowed us to obtain this data at the level of each stock index in the sample of the capital markets considered.

The Amihud indicator calculates a lack of liquidity, respectively:

$$
\text { Amihud }=\frac{1}{T} \sum_{t=1}^{T} \frac{\left|r_{t}\right|}{\$ V_{t}}
$$

where $\mathrm{T}$ represents the number of days taken into account, $\$ V_{t}$ is the volume expressed in euros, and $r_{t}$ represents the logarithmic efficiency of day $\mathrm{t}$.

For our case, weekly returns calculated for each Wednesday day (Diebold Yilmaz recommendation) were taken into account. Therefore, the Amihud liquidity indicator was calculated by estimating the daily returns for the week from the last day of Wednesday to the current Wednesday day and the volume values for the same period. 
Subsequently, the Amihud values were standardized by extracting the mean and dividing the standard deviation of the entire series and reversed in order to be transformed into levels that express liquidity.

In Figure 6 are presented the results of applying the Diebold-Yilmaz model with the same properties as in the case of the use of yields and volatilities (4 prediction periods and 2 lags).

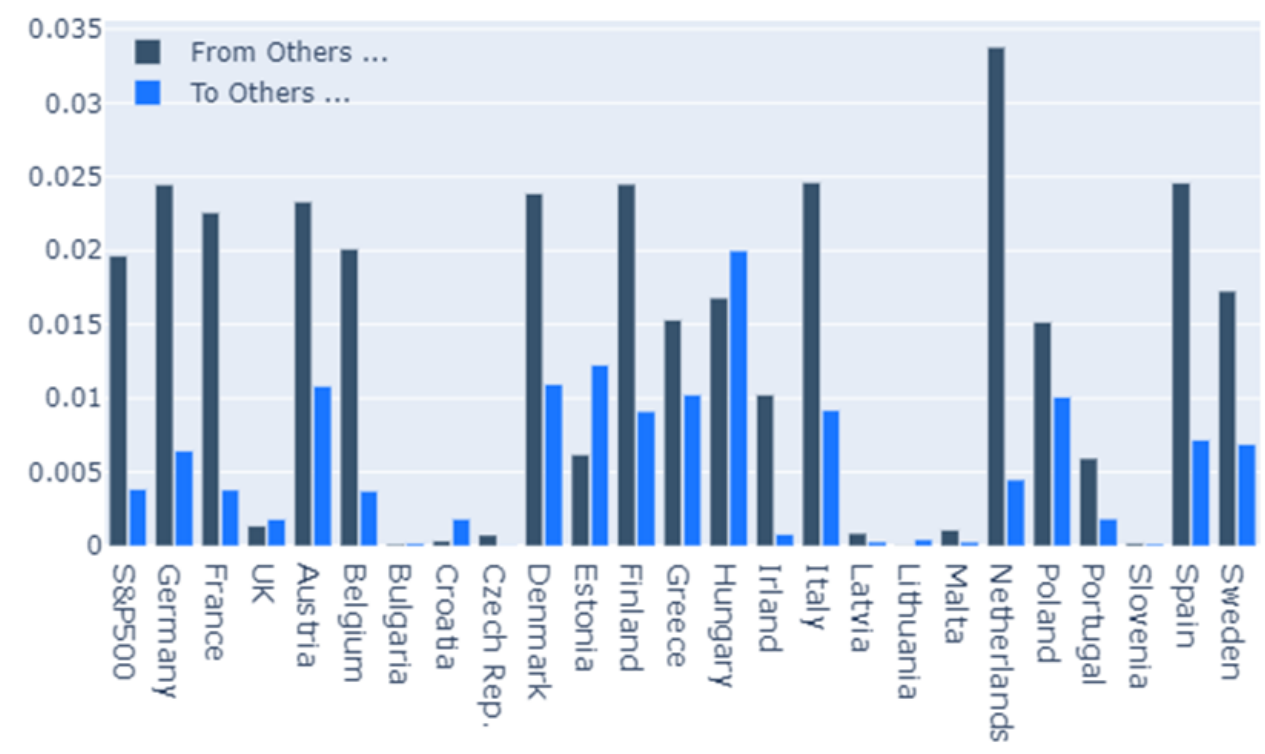

Figure 6. The spillover effect for Romania throughout the analysed period for the transmission of shocks at the liquidity level measured with the Amihud indicator

The results applied to the Romanian situation, corresponding to the values expressed in Figures 4 and Figure 5, show us that the liquidity in Romania is rather passive, receiving shocks from the other countries and giving very little to the others. The major issuers are the Netherlands, Italy, Austria, Spain, Germany and the USA, respectively the developed countries, which generally emit trading signals as a result of the global economy. Romania transmits shocks only to countries in the region, which demonstrates a rather isolated market status.

In order to obtain a broader picture of how the spillover effect manifests for the entire period analysed, estimates were resumed on a 100-day moving sample. The statistical properties of the spillover effect on shocks received from others and given to others are presented in Figure 7. 


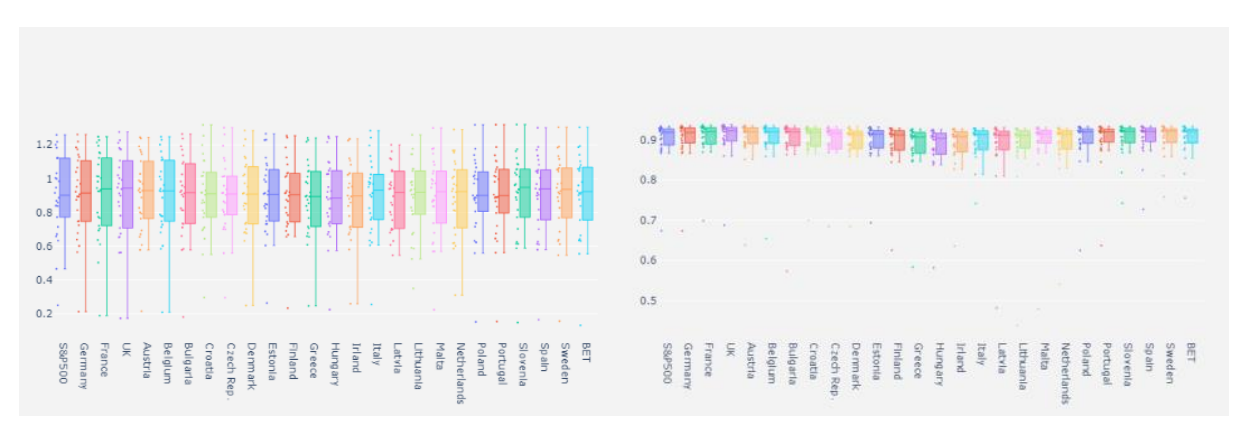

Figure 7. Statistical properties of the received (left) and transmitted (right) spillover for each country in the sample, for repeated estimates made on 100day samples at the yields' level

The dynamics of these transmissions reflect the existence of lower values in the case of shocks transmitted than those received. However, the distribution of shocks is more stable for all receivers. We can conclude that, in terms of the dynamics of shocks for the series of yields, the shocks received are more volatile than the shocks yielded by each country.

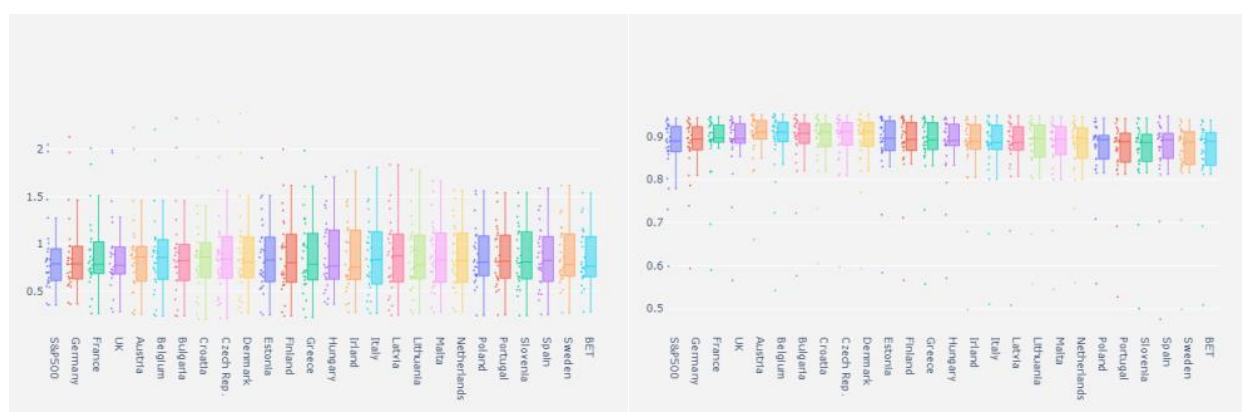

Figure 8. Statistical properties of the received (left) and transmitted (right) spillover for each country in the sample, for repeated estimates made on 100day samples at the volatilities' level

The same result can be extracted from the analysis of the dynamics of the mode of transmission of shocks at the level of volatilities: the yielded shocks tend to have a more balanced distribution, but with significant levels of extreme values (outliers) compared to the shocks received for all the countries analysed (Figure 8).

To complete the picture of these dynamics, our analysis continued with the recovery of these estimates for the evolution of the transmission of shocks at the liquidity level, calculated using the Amihud indicator. The results are presented in the graph in Figure 9.

DOI: $10.24818 / 18423264 / 55.1 .21 .03$ 


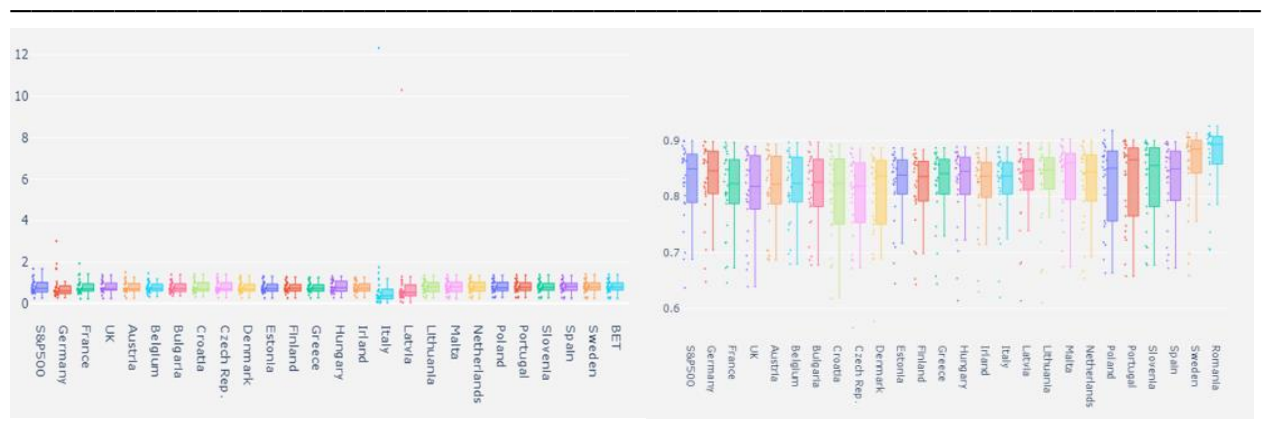

Figure 9. Statistical properties of the received (left) and transmitted (right) spillover for each country in the sample, for repeated estimates made on 100day samples at the liquidity level

The dynamics of the shocks related to the transmission of liquidity retain the same properties as those related to the shocks' distributions extracted from the level of yields and volatilities.

The values of the shocks yielded by each country are lower than those of the shocks received. In addition, the shocks received tend to reach extremely high values especially for Italy and Germany.

\section{Conclusions}

The study of the contagion phenomenon allows an understanding of how the shocks transmitted from the global economy can affect the dynamics of the financial markets of a certain country. This section analyses the spillover phenomenon, which refers to the transmission of shocks from one financial market to another.

In the literature, this phenomenon is mainly discussed at the volatility level (which denotes the risk and uncertainty of financial assets), respectively a description of how the magnitude of the returns is transmitted from one market to another, or from one asset to another. The spillover phenomenon aims to quantify the extent to which financial markets or financial assets tend to transmit shocks.

This study uses the Diebold-Yilmaz methodology to study how the Romanian capital market reacts to shocks transmitted from foreign capital markets on several channels: the direct one at the yields' level, the one at volatilities' level and the one at liquidities' level.

The analysis shows the statistical properties of these forms of shock transmission on each of the three channels, for a group of developed, emerging and frontier countries. The main objective is to characterize the way the Romanian capital market responds to these shocks.

In general, it can be said that Romania receives more spillover than it yields, on each of the three channels. The most important impact comes from the developed countries of the region, namely Austria, Germany, the Netherlands and to a lesser extent from the USA. As for the links with the smaller capital markets in 
Transmission of External Shocks on the Romanian Capital Market

the region, Romania has a tendency to receive spillover from Czech Republic and Poland, and to exchange shocks with Bulgaria and Hungary.

\section{REFERENCES}

[1]Amihud, Y. (2002), Illiquidity and Stock Returns: Cross-Section and Time Series Effects. Journal of Financial Markets, 5: 31-56;

[2]Baba, Y., Engle, R. F., Kraft, D., Kroner, K. F. (1990), Multivariate

Simultaneous Generalized ARCH. Mimeo, Department of Economics, University of California, San Diego;

[3]Barndorff-Nielsen, O. E., Kinnebrock, S., Shephard, N. (2008), Measuring Downside Risk - realised Semivariance. OFRC Working Papers Series 2008, Oxford Financial Research Centre;

[4]Barndorff-Nielsen, O. E., Shephard N. (2002), Econometric Analysis of Realised Volatility and Its Use in Estimating Stochastic Volatility Models.

Journal of the Royal Statistical Society, Series B, 64: 253-280;

[5]Barunik, J., Kocenda, E., V'acha, L. (2016), Asymmetric Connectedness on the US Stock Market: Bad and Good Volatility Spillovers. Journal of Financial Markets, 27: 55-78;

[6]Bekaert, G., Harvey, C. (1997), Emerging Equity Market Volatility. Journal of Financial Economics, 43: 29-77;

[7]Black, F. (1976), Studies of Stock Market Volatility Changes. Proceedings of the American Statistical Association, Business and Economics Statistics Section;

[8]Cappiello, L., Engle, R.F., Sheppard, K. (2006), Asymmetric Dynamics in the Correlations of Global Equity and Bond Returns. Journal of Financial

Econometrics, 4: 537-572;

[9]Christie, A. A. (1982), The Stochastic Behavior of Common Stock Variances: Value, Leverage and Interest Rate Effects. Journal of Financial Economics, 10:

407-432;

[10]Claessens, S., Forbes, K. J. (2001), International Financial Contagion.

Boston, Dordrecht and London: Kluwer Academic Publishers;

[11]Diebold, F. X., Yilmaz, K. (2009), Measuring Financial Asset Return and Volatility Spillovers, with Application to Global Equity Markets. Economic Journal, 119: 158-171;

[12]Diebold, F. X., Yilmaz, K. (2012), Better to Give than to Receive: Predictive Directional Measurement of Volatility Spillovers. International Journal of Forecasting, 28: 57-66;

[13]Engle, R. (2002), Dynamic Conditional Correlation: A Simple Class of Multivariate Generalized Autoregressive Conditional Heteroskedasticity Models. Journal of Business and Economic Statistics, 20: 339-350;

DOI: $10.24818 / 18423264 / 55.1 .21 .03$ 
Gheorghe Hurduzeu, Radu Lupu, Iulia Lupu, Radu Ion Filip

[14]Engle, R. F., Ito, T., Lin, W-L. (1990), Meteor Showers or Heat Waves? Heteroskedastic Intra-daily Volatility in the Foreign Exchange Market.

Econometrica, 58(3): 525-542;

[15]Eun, C. S., Shim, S. (1989), International Transmissions of Stock Market

Movements. Journal of Financial and Quantitative Analysis, 24: 241-256;

[16]Forbes, K. J., Rigobon, R. (2002), No Contagion, Only Interdependence:

Measuring Stock Market Comovements. Journal of Finance, 57: 2223-2261;

[17]Leachman, L. L., Frances, B. B. (1996), Equity Market Return Volatility:

Dynamics and Transmissions Among G7 Countries. Global Finance Journal, 7: 27-66;

[18]Lupu, I. (2015), European Stock Markets Correlations in a Markov

Switching Framework. Romanian Journal of Economic Forecasting, XVIII (3):

103-119;

[19]Lupu, I. (2012), The Theory of International Financial Contagion, Financial

Studies, 4(58): 35-42;

[20]Miyakoshi, T. (2003), Spillovers of Stock Return Volatility to Asian Equity

Markets from Japan and the US. Journal of International Financial Markets, Institutions and Money, 3(4): 383-399;

[21]Moagăr-Poladian, S.; Clichici, D.; Stanciu, C.-V.(2019), The Comovement of Exchange Rates and Stock Markets in Central and Eastern Europe.

Sustainability, 11(14): 3985;

[22]Ng, A. (2000), Volatility Spillover Effects from Japan and the US to the Pacific-Basin. Journal of International Money and Finance, 19: 207-233;

[23]Nițoi, M., Pochea, M. M. (2020), Time-varying Dependence in European

Equity Markets: A Contagion and Investor Sentiment Driven Analysis. Economic Modelling, 86: 133-147;

[24]Pesaran, M., Shin, Y. (1998), Generalized Impulse Response Analysis in Linear Multivariate Models. Economics Letters, 58(1): 17-29;

[25]Wei, K., Liu, Y., Yang, C., Chaung, G. (1995), Volatility and Price Change Spillover Effects across the Developed and Emerging Markets. Pacific-Basin Finance Journal, 3(1): 113-136. 